$\xi=$

\title{
Trend Detection of Drug Abuse Using Multivariate Analysis in Malaysia During the Years 2005 to 2015
}

\author{
Izwan Arif Azizan $^{1 *}$, Hafizan Juahir ${ }^{1}$, Mohd Ekhwan Toriman' ${ }^{2}$ Mahadzirah Mohamad ${ }^{3}$. Norfazillah Abdullah', \\ Mohd Hanif Abdullah ${ }^{1}$ \\ ${ }^{I}$ East Coast Environmental Research Institute, Universiti Sultan Zainal Abidin, Gong Badak Campus, 21300 Kuala Terengganu, \\ Terengganu, Malaysia \\ ${ }^{2}$ School of Social Development and Environmental Studies, Faculty of Social Science and Humanities, Universiti Kebangsaan Malaysia, \\ 43600 UKM Bangi, Selangor, Malaysia \\ ${ }^{3}$ Faculty of Economics and Management Sciences, Universiti Sultan Zainal Abidin, Gong Badak Campus, 21300 Kuala Terengganu, \\ Terengganu, Malaysia \\ *Corresponding author E-mail: hafizanj@gmail.com@unisza.edu.my
}

\begin{abstract}
This study aims to dismantling number drug abuser, cohort of age and drug type effects to improve our understanding of these trends and suggested groups for target intervention by stakeholders to effectively reduce resultant harms. Data of the study involving number of drug abuser, cohort of age (8 groups: < 13, 13-15, 16-19, 20-24, 25-29, 30-34, 35-39, > 40) and drug type was obtained by reviewing annual report of National Anti-Drug Agency (NADA) of Malaysia during 2009 to 2015. Descriptive statistics were applied to give distribution rate and patterns of the data. Cluster analysis then performed to grouped age cohort and drug type into homogenous clusters. Mann - Kendall test were then applied at 5\% interval level to identify any significant trends existed in all clusters. The result showed that age can be group into 3 clusters namely low-age cases, moderated-age cases and high-age cases, while for drug type 3 clusters were also created, low-drug type, moderate-drug type and high-drug type. Lastly, trend test shows that high-drug type (opiate) have very significant upward trend $\mathrm{p}<0.05$. Therefore, preventive strategies can be focus on young adult and opiate abused as it can greatly help reduce number of drug abuser in Malaysia.
\end{abstract}

Keywords: Drug, drug abuse, cluster analysis, Mann - Kendall test, trend and Malaysia.

\section{Introduction}

Drug abuse is one of the major problems affecting mankind around the world. According to World Drug Report, 1 out of 20 people ranging from age 15 to 64 years involve in illicit drug use in 2013 which about 246 million people. This number show an increase of 3 million from previous years however the increase was align with total increase of global population, therefore, drug abuse cases remain stable along the years. In addition, it is estimated that around 27 million or 1 out of 10 people who used drug is a problem user either they are drug dependence or drug use disorder. The effects of drug abuse are huge as it brings negative impacts towards a person for instance physical health including HIV and Hepatitis, affect brain structure and its cognitive functions. Furthermore, drug abuse increase crime rates and domestic violence, joblessness, homelessness, bring down economy and can greatly reduce human population as it kills 187,100 people worldwide in 2013 alone [1].

In Malaysia, drug abuse has always become one of the major threats to the national harmony since long time ago. Malaysia is propinquity to Thailand, Myanmar and Laos which also known as Golden Triangle countries in Southeast Asia that produces illegal drugs [2]. This geographical aspect somehow intensifies drug abuse in Malaysia. The beginning of drug abuse in Malaysia was recorded before independence of Malaya. During this period, most of drug abuser was immigrants from China who brought by British to work in mine area. Opium was the main drug abused by the immigrant during that time. After 1960s, the pattern shifted from Chinese to Malay as the main ethnic involved in drug abuse when the young adult was influenced by 'Hippy' culture from the west and this pattern remain until today. This trend however keeps increasing until 1980s which lead Malaysian Government to declared drug abuse (heroin during the time) as national threat in February 1983. During the same year, Anti - Drug Committee (JKAD) and Anti - Drug Task Force (PAD) was established which reports to the National Security Council in all aspects of the drug problem. In addition, Malaysian Government also has implemented death mandatory as legislation towards people who smuggled drug (heroin) for more than 15 grams and 2 years compulsory of rehabilitation program under strict surveillance for people who positive for heroin. Later in 1996, the government has incorporated Drug Treatment and Rehabilitation Division, Ministry of Interior and Narcotics Task Force, Department of the Prime Minister to be a single agency called the National Drug Agency (NDA) which changes to National Anti - Drug Agency (NADA) in 2004 [3].

As global threat, it is challenging and rewarding to study epidemiology of drug abuse as lots of groups become alert on this public health problem nature and its impact towards social, communities, economies and countries. Therefore, studies of drug abuse will deserve fair attention from policy makers, researchers and government in particular. The objective of this study is to classify the 
data of drug abuse in Malaysia according to homogenous cluster for better understanding. The clusters were then compared to understand the associations between their profile plots. Lastly, these clusters were analyzed to identify existence of significant trends.

\section{Methodology}

\subsection{Description of Study Area}

Malaysia is a democratic country and federal constitutional monarchy. Located at the Southeast Asia with total area of 330,803 square kilometers and surrounded by Singapore, Thailand, Brunei and Indonesia. Malaysia is divided into two regions which are Peninsular Malaysia and East Malaysia separate by South China Sea.

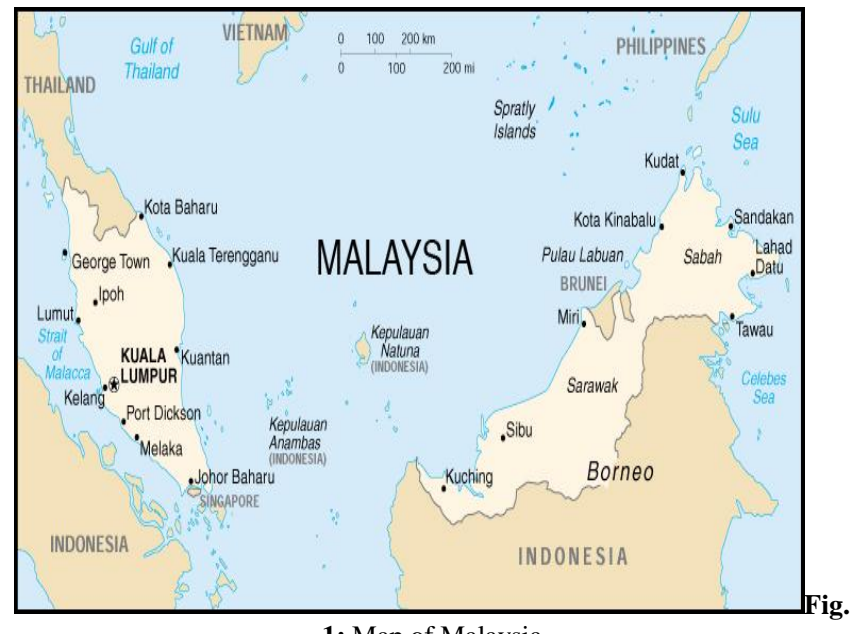

1: Map of Malaysia

It consists of thirteen states and three federal territories with current total population of 31.7 million people making it 44th most populous country. Since year 2000, population in Malaysia increase steadily from 23.5 million to 31.7 million people in 2016 . People with age $15-64$ years old are the highest group followed by adolescent age $0-14$ and lastly senior citizen with the age above 64 years old (Table 1). Population of Malaysia comprises of many races living harmonically with one another namely Malay which is the vast majority $(68.6 \%)$, Chinese, the second larges races $(23.4 \%)$, Indians, third largest races $(7 \%)$ and other minority ethnic such as Kadazan, Iban and others $(1 \%)$.

Table 1: Total population of Malaysia according to age

\begin{tabular}{cccc}
\hline & \multicolumn{3}{c}{ Population (million) } \\
\hline Year & 2000 & 2010 & 2016 \\
Total & 23.5 & 28.6 & 31.7 \\
$0-14$ years & 8.0 & 7.8 & 7.8 \\
$15-64$ years & 14.6 & 19.3 & 22 \\
Above 64 years & 0.9 & 1.4 & 1.9 \\
\hline
\end{tabular}

\subsection{The Data}

This study estimated drug abuse trends starting from 2005 till 2015 using data obtained from NADA annual report starting from year 2009 until 2015. NADA is the main government agency which responsible for all aspects of the anti-drug action in Malaysia and determine efforts of the country to combat the drug menace in a planned, directed and coordinated in order to create a society free of drugs. The data were divided into two which are according to age of drug abuser and type of drug abused. Based on NADA report, age of drug abuse were separate into several age cohorts starting with below 13 years old, 13 - 15 years old, 16 19 years old, $20-24$ years old, $25-29$ years old, $30-34$ years old, $35-40$ years old and above 40 years old. While type of drug abuse according to NADA consist of several drugs namely opiate, opium, marijuana, cocaine, ATS pills (ecstasy and amphetamine), psychotropic pills and other drugs (codeine, inhalant). It is important to be mention here that there are some unknown data regarding either age or type of drug taken by certain individual. Some of the drug abuser also is polydrug user. Therefore, there certain data would not appear same between age and type of drug abused in some years.

\subsection{Statistical Analysis}

\subsubsection{Cluster Analysis}

Hierarchical agglomerative cluster analysis (HACA) was employed in this study. The purpose of this analysis is to group age and type of drug into several clusters as this method is usual in classifying observations/samples or variables into clusters which have high homogeneity inside the class and high heterogeneity with other class according to selected criteria [4-6]. Ward's method was applied using Euclidean distances to measure similarity in HACA as it is proved to be a very effective method [7-9]. Result achieved from this analysis will be presented in dendogram, which it represent clusters and their proximity [10]. In this study, data regarding age of drug abuser and type of drug were applied with HACA to group the data into three clusters.

\subsubsection{Non - Parametric Trend Test}

Non parametric test or also known as Mann Kendall test is a statistical test widely used for the analysis of trend to identify either there is a significant change upward or downward trend [11] There are two advantages of using this test. First, it is a nonparametric test and does not require the data to be normally distributed. Second, the test has low sensitivity to abrupt breaks due to inhomogeneous time series. Any data reported as non-detects are included by assigning them a common value that is smaller than the smallest measured value in the data set. According to this test, the null hypothesis $\mathrm{H} 0$ assumes that there is no trend (the data is independent and randomly ordered) and this is tested against the alternative hypothesis $\mathrm{H} 1$, which assumes that there is a trend. Both of the cluster analysis and Mann-Kendall test were run by using add-ins software functions in Excel 2007 which is XLSTAT 2014. In addition, to compare the results obtained from the MannKendall test, linear trend lines are plotted for each state using Microsoft Excel 2007. Significant level in this study is tested with 95\% confidence level.

\section{Results and Discussion}

\subsection{Descriptive Analysis}

Generally, data taken from NADA shows that the highest number of drug abuser is during 2005 and decrease rapidly towards 2008 (Figure 2). In this year, number of drug abuse shows the lowest value for these 11 years' time period. However, this number raised again in 2009 and 2010 before decrease nearly 15000 people in 2012. During 2013, the trend continues to rise until 2015. Overall, drug abuser in Malaysia show stable with slightly decrease in their trend.

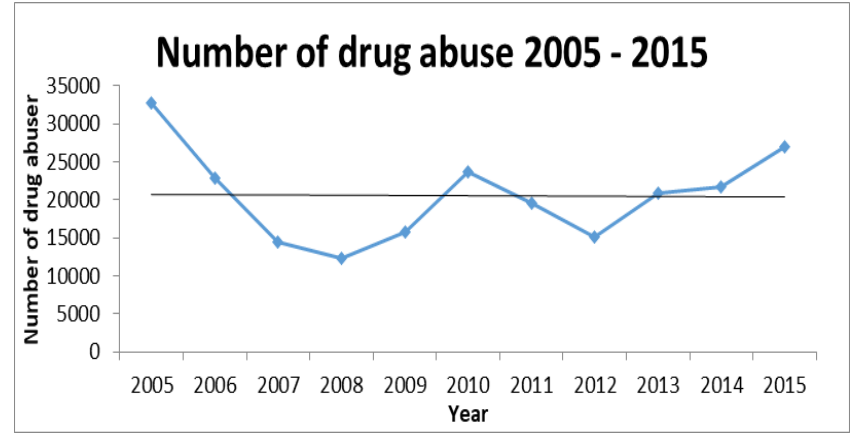

Fig. 2: Number of drug abuse in Malaysia from year 2005 to 2015 
Table 2 depicts age of drug abuse and type of drug abused for year 2005 to 2015 in Malaysia. People with the age above 40 years old have the highest means 4803.55 compared to the other age cohorts. The maximum number for this age is 8211 people during 2005. This figure shows that the highest drug abuser in Malaysia is above 40 years old followed by people who age of $25-29$ years old with mean of 4097.55 and the highest people project by this age is 6495 people also in 2005 . The lowest mean 1.64 however is shown by people with the age below 13 years old or student from primary school with the maximum number of 15 people during 2011.

Descriptive statistics on drug type abused by people shows that opiate is the most abuse drug in Malaysia compared to the other drug with the mean of 8026.18. The maximum number of opiate abuser is during 2015 . This followed by cocaine with mean number 3729.46 (maximum by 8133 people during 2015) and marijuana 2935.82 with highest number of 5275 people (2006). While the lowest drug abused in Malaysia is opium with the mean of 9.46 shows the highest number of drug abuser in 2010 (31 people).

Table 2: Descriptive summary of age cohort and drug type for year 2005 to 2015

\begin{tabular}{|c|c|c|c|c|}
\hline Variable & Minimum & Maximum & Mean & $\begin{array}{c}\text { Std. } \\
\text { deviation }\end{array}$ \\
\hline \multicolumn{5}{|c|}{ Age of drug abuser } \\
\hline Age < 13 & 0.00 & 15.00 & 1.64 & 4.52 \\
\hline Age 13 - 15 & 11.00 & 83.00 & 43.00 & 23.92 \\
\hline Age 16 - 19 & 464.00 & 2610.00 & 1119.00 & 590.84 \\
\hline Age 20 - 24 & 1845.00 & 5467.00 & 3687.00 & 1228.70 \\
\hline Age 25 - 29 & 2405.00 & 6495.00 & 4097.55 & 1176.40 \\
\hline Age 30 - 34 & 2325.00 & 6045.00 & 3679.27 & 1100.39 \\
\hline Age 35 - 39 & 1779.00 & 4786.00 & 2865.73 & 923.97 \\
\hline Age > 40 & 3043.00 & 8211.00 & 4803.55 & 1624.05 \\
\hline \multicolumn{5}{|c|}{ Type of drug abused } \\
\hline Opiate & 440.00 & 16616.00 & 8026.18 & 6154.09 \\
\hline Opium & 0.00 & 31.00 & 9.46 & 9.44 \\
\hline Marijuana & 1389.00 & 5275.00 & 2935.82 & 1561.43 \\
\hline Cocaine & 1131.00 & 8133.00 & 3729.46 & 2285.84 \\
\hline $\begin{array}{c}\text { ATS pills } \\
\text { (ecstasy and } \\
\text { amphetamine) }\end{array}$ & 167.00 & 4525.00 & 997.82 & 1268.52 \\
\hline $\begin{array}{c}\text { Psychotropic } \\
\text { pills }\end{array}$ & 1.00 & 752.00 & 203.82 & 270.00 \\
\hline $\begin{array}{c}\text { Others (Co- } \\
\text { deine and } \\
\text { Inhalant) }\end{array}$ & 26.00 & 754.00 & 199.00 & 220.52 \\
\hline
\end{tabular}

\subsection{Classification of Age and Type of Drug}

This section examines the number of cases occur between year 2005 and 2015 by using HACA in order to classify age of drug abused and type of drug they abused based on the similarity level between each category. HACA is an important analysis tool to evaluate variation among data set to group the data into similar nature and separate it to perform another group if the nature of data is different. Result from this analysis towards both data set shows that each data set can be grouped into 3 three clusters (Figure 3 and Figure 4).

Cluster analysis is important in this study to regroup 8 age cohort into proper group. Annual report by NADA gave unequal age range in each cohort. Direct use of this data without performing cluster analysis can lead to bias result. Range given by NADA are $<13,13-15,16-19,20-24,25-29,30-34,35-39$, > 40. Therefore, application of cluster analysis will group these age cohort properly according to their similarities in number of abuser.

Cluster 1 represent cluster group with low - age cases (LAC) which include adolescent who age 19 years old and below $(<13$ years old, $13-15$ years old and $16-19$ years old). Compare to other age cohort, adolescent have the lowest cases involve with drug abuse. While cluster 2 shows moderate - age cases (MAC) consist of senior citizen age 40 years old and above. Lastly cluster
3 consist young adult and adult with the age between 20 years old until 39 years old. Cluster 3 shows the highest - age cases (HAC) among 8 age cohorts.

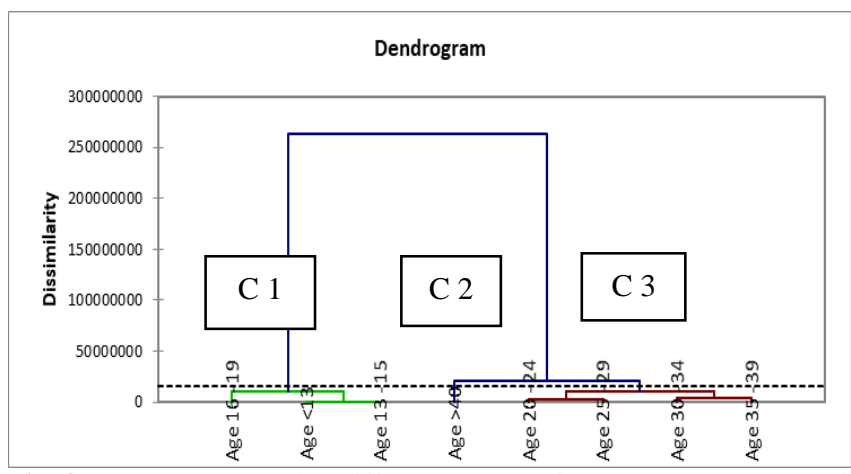

Fig. 3: Dendogram showing different clusters of age based on number of cases

At the same time, data regarding type of drug also was divided into three clusters. Contradict with cluster sequence in age data, dendogram in this category result in cluster 1 with the highest drug type (HDT) abused in Malaysia which refer to opiate. While cluster 2 consist of ATS pills such as amphetamine and ecstasy, psychotropic pills, opium and other drug (codeine and inhalant) are the lowest type of drug abused by Malaysian also known as low - drug type (LDT). Lastly, marijuana and cocaine were group in cluster 3 which represent moderate - drug type (MDT) abused throughout the year.

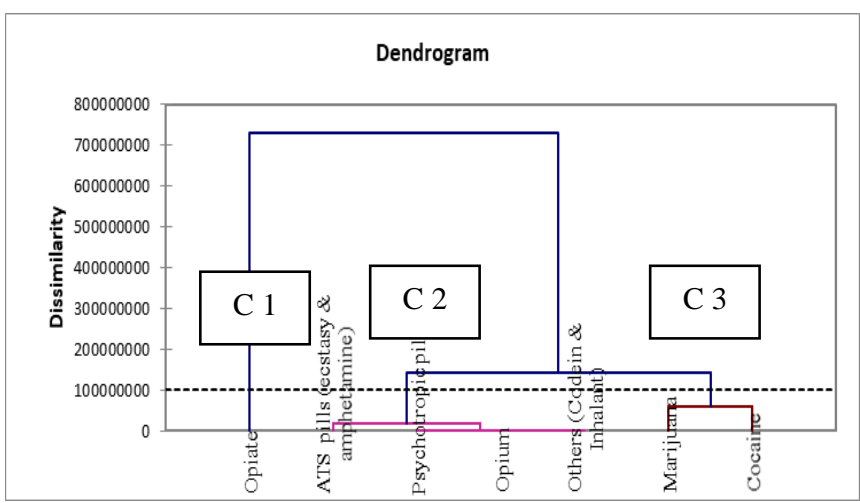

Fig. 4: Dendogram showing different clusters of drug type based on number of cases

\subsection{Trend Analysis}

Application of Mann - Kendall trend test towards all the clusters shows that despite the increasing or decreasing trend in age and type of drug only HDT show significant upward trend at $\mathrm{p}<0.05$ while the other cluster does not show any significant changes (Table 3 ). Trend of opiate have significantly increase ( $\mathrm{p}<0.05)$ compared to other drugs is because of increased supply of opiate. According to World Drug Report (2015) global opium poppy cultivation reached its highest level since 1930s. Therefore, production of opiate might possibly reflect by this increase in market. Another strong factor that causes this significant increase is due to the ability to cure addiction. In reality, the evidence shows that even the most elaborate form of treatment can only produce minimal success which is less than $10 \%$ effectiveness [3]. This shows that more than $90 \%$ drug abuser mostly opiate going relapse and some of them abused opiate within 6 months after being discharged from the centers [12]. This is due to the fact that is not easy to cure addiction because it is a chronic relapsing disorder and it needs many treatment programs such as psychological and social intervention together with pharmacological treatment and high consistent cost of operations. Therefore, single focus treatment such 
as Serenti centers which confine only to rehabilitations programs received reported as it give poor result success and inefficient use of public funding [13-15].

Although the number of drug abuser decrease in 2015, this problem should not be taken lightly. Figure 5 shows trend of age and drug type based on their cluster in Malaysia. Opiate still highly increase as well as marijuana and cocaine. In order to make Malaysia free from drug abuse, number of cases or drug abuser must be below $1 \%$ from total populations. Therefore, the journey is far from over as many steps in preventing drug abused should be highlight by policy-makers, Malaysian government and respected parties.

Table 3. Mann - Kendall Test of trend for age and drug type clusters

\begin{tabular}{|c|c|c|c|}
\hline \multirow{2}{*}{ Variable } & \multicolumn{3}{|c|}{ Mann - Kendall Test } \\
\cline { 2 - 4 } & $\mathrm{S}$ & $\mathrm{p}$-Value (Two-Tailed) & Trend \\
\hline LAC & 9.00 & 0.54 & $\mathrm{NT}$ \\
\hline MAC & -1.000 & 1.000 & $\mathrm{NT}$ \\
\hline HAC & 5.00 & 0.761 & $\mathrm{NT}$ \\
\hline LDT & -7.00 & 0.65 & $\mathrm{NT}$ \\
\hline MDT & 1.00 & 1.00 & $\mathrm{NT}$ \\
\hline HDT & 33.00 & 0.01 & $\mathbf{\uparrow}$ \\
\hline \multicolumn{4}{|c}{ Note: NT - No trend } \\
\hline
\end{tabular}

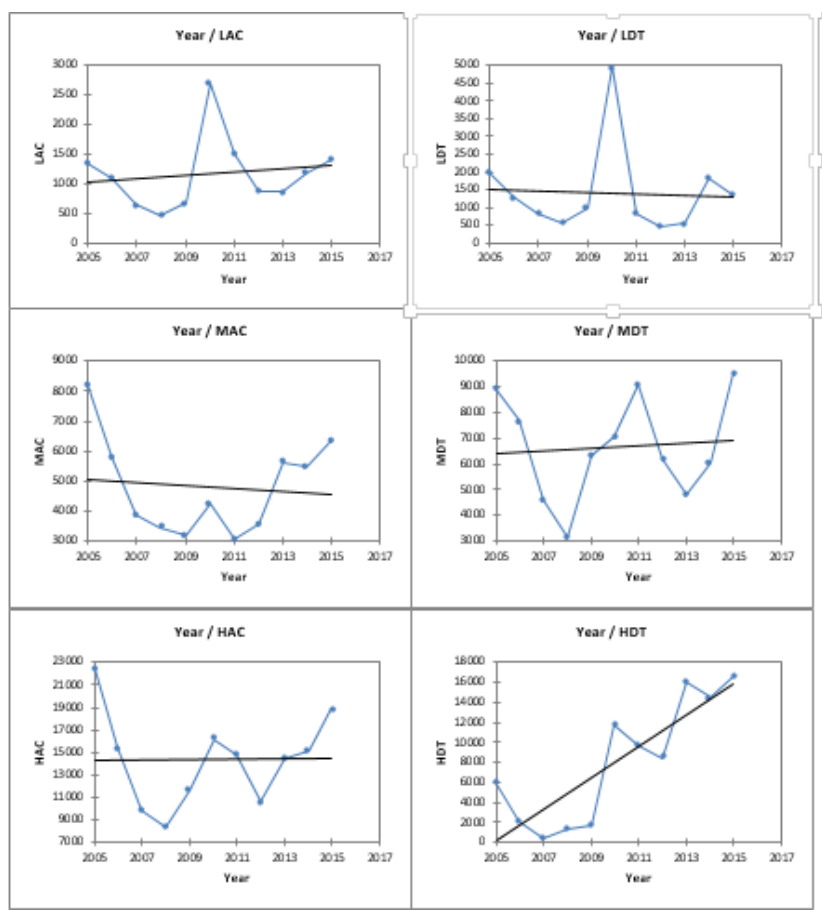

Fig. 5: Trend of age and drug type in Malaysia during 2005 - 2015

\section{Conclusion}

To study trend of drug abuse in Malaysia, data regarding age of drug abuser and drug type were use from year 2005 to2015. Descriptive statistics shows that the highest mean is drug abuser with the age of 40 and above and lowest mean is age below 13 years old. On the other hand, opiate show the highest drug type abused by Malaysian while the lowest drug abused is opium. Cluster analysis result in classifications of both categories of data into 3 clusters namely LAC, MAC and HAC for age and LDT, MDT and HDT for drug type. Comparison between trends of cluster shows similar pattern between LAC and LDT cluster while people group in MAC and HAC shifted abused of drug from marijuana and cocaine towards opiate starting 2009. Trend analysis however indicates that only HDT have very significant upward trend $\mathrm{p}<$ 0.05 . Overall trend for number of drug abuser in Malaysia show decrease in numbers however abused of opiate continue to peak in 2015.

\section{Acknowledgement}

The authors wish to give special thanks to Department of Higher Education, Ministry of Education Malaysia, National Anti - Drug Agency of Malaysia and UniSZA for providing general assistants to this project. This paper is funded under the Niche Research Grant Scheme (NRGS) grant RR057 Universiti Sultan Zainal Abidin (UniSZA) Kuala Terengganu.

\section{References}

[1] Lee, S. F., Hsu, J., \& Tsay, W. I. (2013). The trend of drug abuse in Taiwan during the years 1999 to 2011. Journal of Food and Drug Analysis, 21(4), 390-396.

[2] Ibrahim, F., \& Kumar, N. (2009). Factors effecting drug relapse in Malaysia: An empirical evidence. Asian Social Science, 5(12), 37.

[3] Rusdi, A. R., Robson, N. Z. M. H., Muhammad, M. A. Z., \& Mohamad, H. H. (2008). A fifty-year challenge in managing drug addiction in Malaysia.

[4] Ismail, A., Toriman, M. E., Juahir, H., Zain, S. M., Habir, N. L. A., Retnam, A., ... \& Azid, A. (2016). Spatial assessment and source identification of heavy metals pollution in surface water using several chemometric techniques. Marine Pollution Bulletin, 106(1), 292-300.

[5] Al-Odaini, N. A., Zakaria, M. P., Zali, M. A., Juahir, H., Yaziz, M. I., \& Surif, S. (2012). Application of chemometrics in understanding the spatial distribution of human pharmaceuticals in surface water. Environmental Monitoring and Assessment, 184(11), 67356748.

[6] Juahir, H., Zain, S. M., Aris, A. Z., Yusof, M. K., Samah, M. A. A., \& Mokhtar, M. (2010). Hydrological trend analysis due to land use changes at Langat River Basin. Environment Asia, 3(2010), 20-31.

[7] Juahir, Hafizan, Sharifuddin M. Zain, Mohd Kamil Yusoff, TI Tengku Hanidza, AS Mohd Armi, Mohd Ekhwan Toriman, and Mazlin Mokhtar. Spatial water quality assessment of Langat River Basin (Malaysia) using environmetric techniques. Environmental Monitoring and Assessment 173, no. 1-4 (2011): 625-641.

[8] Adiana, G., Juahir, H., Joseph, B., \& Shazili, N. A. M. (2017). Tracing the sources of lead $(\mathrm{Pb})$ in Brunei Bay, Borneo by using integrated spectrometry ICP-MS and chemometric techniques. Marine Pollution Bulletin, 123(1-2), 232-240.

[9] Ghazali, A., Shazili, N. A. M., Bidai, J., \& Shaari, H. (2016). The spatial distribution of $\mathrm{Al}, \mathrm{Fe}, \mathrm{Cu}, \mathrm{Cd}$ and $\mathrm{Pb}$ in the surface sediment of Brunei Bay, Borneo during the southwest and northeast monsoons. Journal of Sustainability Science and Management, 11, 93106.

[10] Forina, M. Armanino, C. \& Raggio, V. 2002. Clustering with dendograms on interpretation variables. Analytica Chemica Acta, 454, $13-19$.

[11] Juahir, H., Zain, S. M., Aris, A. Z., Yusof, M. K., Samah, M. A. A., \& Mokhtar, M. (2010). Hydrological trend analysis due to land use changes at Langat River Basin. Environment Asia, 3(2010), 20-31.

[12] Habil, M. H., \& Mohd. Mustafa Ali. (2001). Managing drug addiction: Mission is possible. Salafi.

[13] Chawarski, M. C., Mazlan, M., \& Schottenfeld, R. S. (2008). Behavioral drug and HIV risk reduction counseling (BDRC) with abstinence-contingent take-home buprenorphine: A pilot randomized clinical trial. Drug and Alcohol Dependence, 94(1), 281-284

[14] Mazlan, M., Mazlan, M., Schottenfeld, R. S., Mazlan, M., Schottenfeld, R. S., Chawarski, M. C., ... \& Chawarski, M. C. (2006). New challenges and opportunities in managing substance abuse in Malaysia. Drug and Alcohol Review, 25(5), 473-478.

[15] Habil, H. (2001). Managing heroin addicts through medical therapy. 